\title{
La insustentabilidad en las áreas marginales de México. Policías comunitarias y grupos de autodefensa
}

\section{Resumen:}

La historia de México, sobre todo con la imposición de las políticas neoliberales, ha dejado en evidencia cómo el Estado, ha permitido la exclusión y el abandono a la ciudadanía, sobre todo este México rural. Y de manera paralela, ante una desigualdad social y económica, pareciera que, en consecuencia, se vive una fuerte carencia del Estado de Derecho. Ante esta situación de olvido, los habitantes han tenidoque ver diferentes formas deorganización, por ejemplo, en las zonas rurales e indígenas han decidido armarse para protegerse de la creciente delincuencia común y organizada. Al

\section{Cómo citar}

Monroy Ojeda, Carla. La insustentabilidad en las áreas marginales de México: Policías comunitarias y grupos de autodefensa. Revista Constructos Criminológicos. Recuperado a partir de https:// constructoscriminologicos.uanl.mx/index.php/cc/ article/view/6

* https://orcid.org/0000-0002-3609-346X

Universidad de Ciencias de la Seguridad, México menos en la región de La Montaña de Guerrero, ya tienen más de 2 décadas que conformaron su policía comunitaria; los grupos de autodefensa presentes en 10 estados más han ido tomando presencia casi de forma paralela a la creciente violencia relacionada con la delincuencia organizada.

Los grupos de autodefensa se pueden observar como síntoma de hartazgo y que refleja el deterioro de la sustentabilidad entre el gobierno, el Estado y la ciudadanía. Por otro lado, la policía comunitaria es un sistema de justicia basada en sus usos y costumbres, fortalecida por la ineptitud y corrupción de las autoridades, ambas son formas de vida que han tomado muchas de las áreas marginales.

Es necesario conocer y difundir lo que significan estos movimientos y qué es lo que los impulsa antes de que su existencia sea criminalizada y desvirtualizada, como ocurrió en Michoacán (Tierra Caliente) en donde buscaban la paz y seguridad que no lograban tener. 
Palabras Clave: Sustentabilidad, Grupos De Autodefensa, Policía Comunitaria, Violencia, Crimen Organizado.

\begin{abstract}
The history of Mexico, especially with the imposition of neoliberal policies, has made it clear how the State has allowed the exclusion and abandonment of citizens, especially this rural Mexico. At the same time, in the face of social and economic inequality, it seems that, as a result, there is a serious lack of the state of law. Due with this situation of oblivion, the inhabitants have had to see different forms of organization, for example, in rural and indigenous areas they have decided to arm themselves to protect themselves from the growing common and organized crime.
\end{abstract}

At least in the region of La Montaña de Guerrero, they already have more than 2 decades that formed their community police; self-defense groups present in 10 more states have been gaining presence almost in parallel with the growing violence related to organized crime. The self-defense groups can be seen as a symptom of tiredness and reflecting the deterioration of sustainability between the government, the state and the citizenry. On the other hand, the community police is a justice system based on its customs and customs, strengthened by the ineptitude and corruption of the authorities, both of which are ways of life that have taken many of the marginal areas.

It is necessary to know and disseminate what these movements mean and what drives them before their existence is criminalized and devirtualized, as happened in Michoacán
(Tierra Caliente) where they sought peace and security that they could not have.

Keywords: Sustainability, Self-Defense Groups, Community Policing, Violence, Organized Crime.

\section{EL CONTEXTO DE LAS ÁREAS RURALES EN MÉXICO}

La vida rural en México es el reflejo de una historia difícil y de injusticias. Tiempos anteriores a la Revolución mexicana se evidenciaban condiciones de vida de abandono y deficientes posibilidades de desarrollo. A pesar de haber pasado por esta revuelta tan sanguinaria, la realidad actual no es diferente. Como expresa Padgett y Martínez, "Cada área rural mantiene y vive una realidad distinta a la del resto del país, es una república dentro de otra." (2012). Además de ello, las áreas rurales, se caracterizan por su pobreza, que si bien, no hay relación suficiente que relacione pobreza con violencia (Robles, F., Hernández, C. y Hernández, N. 2019), sí hay una relación entre violencia y desigualdad social. Esta vinculación explicativa de la delincuencia y de la violencia, es una herramienta, o un mecanismo recurrente, pero como se ha comentado, no es una ecuación lineal. Estos fenómenos no se resuelven: a, por lo tanto, B y entonces C. Igualmente, no habría porqué asumir que; pobreza genera violencia y desarrollo y bienestar, la contienen. Estas últimas no pueden ser consideras como causas decisivas de la inseguridad, pues al relacionarlas se dejan de lado otros aspectos de la gobernación y de la cultura regional o 
local que inciden tanto en la desigualdad como en la violencia (Robles, F., Hernández, C., y Hernández, N., 2019).

Además de las condiciones de pobreza y desigualdad en las que ha vivido el área rural mexicana, se entretejen un sinfín de causas que cualquier aproximación al entendimiento absoluto del origen del problema, debe ser planteada de manera integral. No se puede permitir la presencia de modelos analíticos simples, porque se está frente a esta realidad compuesta por estructuras-agentes-dinámicasinterrelaciones (Robles, F., Hernández, C. y Hernández, N. 2019). Así como por ejemplo, para un diagnóstico del delito o de política pública, en este tema de vida rural y violencia, el mapa de soluciones, se construye con base a la lectura detallada del área de estudio. Cada zona, cada región del país, la violencia rural en sí misma, tiene su historia, antecedentes, actores, cultura, marco institucional, que le dan su matiz particular. También se debe considerar, la forma de operar de grupos criminales, conflictos religiosos y políticos (previos o presentes), así como la tenencia y uso de la tierra. Como lo manifiesta Inclán, citado en Robles, Hernández y Hernández:

En otras palabras, en el campo mexicano se vive también un conflicto entre: controlsubordinación vs libertadindividualismo. Este equilibrio inestable, provocado por el desajuste en las formas políticas, económicas, sociales y culturales, constituye el caldo en el que se aderezan diversas manifestaciones de la violencia-criminal, social, de género, patrimonial, política y religiosa, entre otras-, las cuales dan cabida a la creación de poderes paralelos sirviéndose de identidades étnicas, religiosas, corporativas o socioeconómicas (Inclán, 2018), en las que puede incluirse al crimen organizado (en Robles, F., Hernández, C. y Hernández, N. 2019)

El área rural mexicana, es una mezcla de lo pasado y lo presente, de olvidos e intentos de inclusión. Es una amalgama perfectamente heterogénea, que muchas veces se absorbe en la profundidad de la sierra y de los Ilanos. Dentro de la del artículo de República Marihuanera se lee el testimonio de un ciudadano:

Puedes ir a las comunidades y ver niños tan desnutridos que tienen los ojos saltones y la panza inflada por las lombrices. Muchas personas beben agua de los arroyos, y los servicios médicos, donde existen, son pésimos. Las clínicas de un consultorio carecen de medicamentos y el trabajo social es mínimo. Hay niños vacunados solo por el favor de rancheros que acomodan tres o cuatro en sus cuatrimotos y los bajan a la clínica más cercana. Y la mayoría de los dueños de esos vehículos son de una u otra forma, parte del negocio de la yerba. $(2012$, p.24)

Contrario a cualquier lógica de desarrollo y crecimiento, observar este tipo de carencias, comparables a las del África Subsahariana, es inadmisible, sin embargo, es el olvido en el que se encuentran, Situación a pesar de que CONEVAL marca un importante avance en el tema de rezago social. 


\section{Evolución de los indicadores de rezago social a nivel nacional}

\section{$2000-2020$}

\begin{tabular}{|c|c|c|c|c|c|}
\hline \multirow{2}{*}{ Indlcadores de rezago soclal } & \multicolumn{5}{|c|}{ Porcentaje } \\
\hline & 2000 & 2005 & 2010 & 2015 & $2020^{*}$ \\
\hline Población de 15 años o más analfabeta & 9.46 & 8.35 & 6.88 & 5.49 & 4.74 \\
\hline $\begin{array}{l}\text { Población de } 6 \text { a } 14 \text { años que no asiste a la escuela } \\
\text { Población de } 15 \text { años y más con educación básica }\end{array}$ & 8.21 & 5.29 & 4.77 & 3.51 & 6.12 \\
\hline incompleta & 52.44 & 45.98 & 41.11 & 35.29 & 29.59 \\
\hline Población sin derechohabiencia a servicios de salud & 56.99 & 49.78 & 33.85 & 17.28 & 26.19 \\
\hline Viviendas con piso de tierra & 13.81 & 9.93 & 6.15 & 3.55 & 3.51 \\
\hline $\begin{array}{l}\text { Viviendas que no disponen de excusado o sanitario } \\
\text { Viviendas que no disponen de aqua entubada de la red }\end{array}$ & 14.12 & 9.90 & 4.66 & 2.83 & 1.93 \\
\hline pública & 15.68 & 11.05 & 11.28 & 5.10 & 3.46 \\
\hline Viviendas que no disponen de drenaje & 21.90 & 11.67 & 8.96 & 6.08 & 4.26 \\
\hline Viviendas que no disponen de energía eléctrica & 4.96 & 6.12 & 1.82 & 1.02 & 0.76 \\
\hline Viviendas que no disponen de lavadora & 48.04 & 39.04 & 33.62 & 30.45 & 27.15 \\
\hline Viviendas que no disponen de refrigerador & 31.51 & 23.22 & 18.00 & 14.76 & 12.36 \\
\hline
\end{tabular}

Fuente: Coneval 2020

En relación a esta situación del rezago, pobreza, violencia, -entre otros factores-, es que el movimiento migratorio tiene gran fuerza en el país, principalmente en estados donde la pobreza persiste, y se considera de "tradición" migratoria, como es el caso de Michoacán, Guanajuato, Estado de México y Zacatecas, principalmente. En el caso de los estados más pobres como lo son Chiapas, Guerrero y Oaxaca ${ }^{1}$ la tradición migratoria es menor debido a la misma carencia de recursos económicos y sociales.

1 De acuerdo con la CONEVAL 2020, los estados con rezago social muy alto son; Chiapas, Oaxaca, Guerrero, Veracruz. Los estados de Michoacán, San Luís Potosí, Puebla, Hidalgo y Campeche tienen la categoría de muy alto.
La actividad económicamente productiva, por excelencia de las zonas rurales en México, es la agricultura. Labor primaria relegada al olvido y abandono por el Estado, y que quien ha sabido aprovechar tal coyuntura ha sido la delincuencia organizada. Se han acercado a los jornaleros a ofrecerles apoyo e ingresos mayores, situación que, debido a la vulnerabilidad, fácilmente es aceptada. "Del maíz, el frijol y el chile comemos, de la marihuana vivimos". (Padgett y Martínez, 2012, p.24). Por lo que agrega el texto:

Así que el cultivo de enervantes se ha convertido en una opción de autoempleo para casi todas las familias campesinas en la región. Esto siempre ha existido, al menos desde que regresaron los primeros braceros 
de Estados Unidos, y más desde hace 10 años.

La política migratoria México- Norteamérica no ha representado un cambio positivo en la calidad de vida de los mexicanos migrantes, ya que no plantea reformas estructurales y sustentables que garanticen la disminución en la inequidad y desigualdad social. Por ejemplo, el caso del Programa Bracero, el discurso oficial lo planteo como una importante oportunidad laboral, pero al término de este no se articuló con alguna otra política de manera tal que se evitara que los trabajadores participantes del Programa quedaran es una especie de limbo o incertidumbre laboral y migratoria.

Las redes migratorias que se generaron durante el Programa Bracero permanecen hasta la fecha, lo que en parte le sigue dando el dinamismo al fenómeno, ya que el tema de la migración tiene causas derivadas como la necesidad económica y de seguridad, sin embargo, estas redes de atracción le dan más empuje. Y en este sentido, bajo esta dinámica interesante, de los factores de expulsión- atracción, es que, la migración sigue siendo la respuesta aparentemente más sencilla a la vulnerabilidad sufrida por el gran sector ciudadano excluido.

Hablando más recientemente, el contexto migratorio mexicano se vio en una terrible situación durante la administración de Donald Trump, periodo en donde se instaló un ambiente de ansiedad y temor, por parte de la comunidad migrante. Llevó a cabo políticas migratorias, sumamente duras; el discurso oficial era la deportación, aplicaba redadas en hogares y lugares de trabajo de los migrantes.
Muchas familias fueron separadas de manera intencional en la frontera, también rescindió el programa DACA, lo que ponía a cientos de miles de jóvenes de origen mexicano en riesgo de ser deportados o arrojados nuevamente a la clandestinidad (Armendares, 2018, p.105).

La migración ha resuelto de manera superficial las necesidades económicas de aquellos migrantes, y a pesar de la dificultad de la travesía, estos la siguen llevando a cabo debido a que las deplorables condiciones de seguridad humana en el país, no han mejorado:

El aumento de la rudeza de las autoridades migratorias en Estados Unidos incidió también en el engrosamiento de las filas de la narcoeconomía de la Tierra Caliente: cada deportado sin trabajo en la región se convierte en campesino, halcón o sicario. (Padgett y Martínez, 2012, p.26).

Tomar la decisión de migrar, en sí misma es muy difícil, por los evidentes riesgos que esta implica, por el distanciamiento con los seres queridos, y por el desconocimiento del destino. Todo esto aunado a que, en varias ocasiones ya se ha intentado previamente, y la misión ha fracasado. Ya sea que el traficante (pollero), los haya abandonado, o que hayan sido capturados y deportados por las autoridades migratorias.

Considerando esta situación de una deportación pronta, (antes de instalarse y emplearse), se enfrentan ante la realidad de pagar la deuda que se generó para realizar el viaje. Muchos de ellos son de extracción rural, por lo que la posibilidad de que el campo les ayude a producir, para solventar esta deuda, es lejana. 
Por lo que, ¿cómo podría negarse la población en aceptar la opción de cosechar de drogas (en este caso marihuana)?, si además se llega a convertir en su única opción. Como pasó en Colombia en tiempos de Pablo Escobar, La Familia Michoacana, el mismo Chapo Guzmán, que reparten dinero a pobres, escuelas, apadrina festejos, hace donativos a iglesias, etc. Por lo que las organizaciones criminales son aceptadas, respetadas y encubiertas por la comunidad que el Estado olvidó.

\section{SUSTENTABILIDAD Y DERECHOS HUMANOS}

La sustentabilidad de acuerdo a la CEPAL se define como:

El desarrollo sustentable no se refiere a una meta tangible ni cuantificable a ser alcanzada en determinado plazo y momento. Se refiere más bien a la posibilidad de mantener un equilibrio entre factores que explican un cierto nivel de desarrollo del ser humano, nivel que es siempre transitorio, en evolución y, al menos en teoría, debería ser siempre conducente a mejorar la calidad de vida de los seres humano. El Ilamado desarrollo sustentable es, en consecuencia, la resultante de un conjunto de decisiones y procesos que deben llevar a cabo generaciones de seres humanos, dentro de condiciones siempre cambiantes, con información usualmente insuficiente, sujetas a incertidumbres y con metas poco compartidas por una sociedad y personas en general no muy solidarias: si el desarrollo sustentable se mantiene en el tiempo se alcanza la sostenibilidad. (1999, p. 3)
Para lograr este utópico objetivo se debe tener la visión de interconectar los sistemas de lo sociocultural, económico y medio ambiental, ya que la calidad de vida del ser humano involucra diferentes aristas. Es contradictorio hablar de sustentabilidad cuando hay condiciones de pobreza y vulnerabilidad tan generalizadas y lacerantes en el país, así como también la constante aniquilación y depredación del medio ambiente es contrario a lo ideal.

En este sentido la directriz de la sustentabilidad deben ser los derechos humanos, y de esta forma el discurso democrático se sustentaría en esta propuesta. De igual forma el diseño de políticas públicas también deben ser regidas por estos derechos de todos los individuos, sin embargo, la inseguridad humana y ciudadana existentes denotan sentido opuesto este precepto.

La participación ciudadana es pieza importante dentro de la complejidad de este concepto, ya que es a través del diálogo ciudadanoinstitución- ciudadano en donde se permitirán visualizar los problemas que persisten y las necesidades apremiantes dentro de la ciudad o comunidad en cuestión. Aguilera observa que, La entrada de la participación ciudadana en la estructura institucional tanto de sujetos (individuales o colectivos) provoca una reordenación administrativa, una mayor integración y corresponsabilidad de los grupos sociales en los asuntos públicos, a la vez que se consigue gestionar el poder político de manera coordinada con otros colectivos. (2008, p.9) Bajo esta idea, el activismo social se podría integrar como una crítica activa hacia asuntos públicos, sin embargo, a veces no tiene recepción de parte de las instituciones ya que 
hay intereses de particulares que buscan ser priorizados sobre lo colectivo. Por mencionar uno de tantos ejemplos, el joven Aldo Zamora asesinado en 2007 por exigir un alto a la tala ilegal de árboles, su delito sigue impune (2011). Esto denota acciones contrarias al interés de lograr una sustentabilidad ambiental, la cual es humana también, ya que al luchar por el medio ambiente y su conservación es luchar por la vida planetaria en su totalidad. El pensamiento que fragmenta y divide a la humanidad del ecosistema, no es sólo antropocéntrico, sino que da facto atropella la visión plural de los pueblos originarios, a quienes la tierra, esta pachamama, les significa mucho más que para los habitantes de las ciudades.

Una de las características de la delincuencia organizada es que está profundamente relacionada con el mismo Estado, el caso de los talamontes (así se les denomina a los grupos delictivos que llevan a cabo la práctica de la tala y tráfico ilegal de madera), es uno de diferentes ejemplos que caben en este espacio. $Y$ es que la corrupción, la ausencia de una cultura de legalidad, la misma complejidad operativa, es lo que va dando fuerza a estos delitos para que se sigan presentando, por otro lado, el monto tan elevado en las transacciones y flujo de divisas, lo que, va ocasionando que se convierta en un proveedor al PIB del país, o en otras palabras, considerándose una actividad económica de alto impacto. Esto aunado a la facilidad y a la rentabilidad de este delito en particular, la relación costo- beneficio del tráfico ilegal de madera, es "muy alta", porque varios países no lo han tipificado como delito y apenas castigan a los traficantes y porque otras actividades delictivas, como el narcotráfico o la trata de personas, cuentan con toda una red global de persecución (Brusco, s/f). Desde la coordinación regional de Gobernanza Ambiental también observan cómo grupos de narcotraficantes han cambiado las drogas por la madera ilegal. La realidad es que las bandas van a seguir delinquiendo y van a buscar nuevas opciones (Brusco, s/f). El tráfico ilegal de madera aumenta en Latinoamérica (efeverde.com)

Como parte de este contexto de la fuerte presencia de las organizaciones criminales, a lo largo del país, y muy arraigado en el México profundo, fue a la par de la Guerra contra el narcotráfico en el 2006 el incremento de la violencia a lo largo del país fue impactante, por lo que había un miedo generalizado en toda la población. Sin embargo, es cuando la misma ciudadanía se da cuenta de cómo las instituciones de seguridad pública fueron superadas por la delincuencia organizada y se vieron involucradas dentro de las mismas organizaciones que buscaban combatir.

Se lee en el artículo de Emeequis:

"¿Siembran todos los policías municipales que conoce?

- Todos.

- ¿Y los estatales?

- Todos.

- ¿Y los federales y soldados que son de aquí?

- Todos, todos... (2012, p. 28)

Es decir que el derecho humano a la seguridad no se está garantizando, sino que se está actuando contrario a este, debido a la impunidad y corrupción que histórica y culturalmente arraigada a la cultura mexicana. 
Constitucionalmente todo mexicano goza de los derechos humanos, por lo que el mismo Estado está obligado a encausar sus esfuerzos, acciones y reformas en este sentido, como lo indica claramente el artículo 1 de la Constitución:

Todas las autoridades, en el ámbito de sus competencias, tienen la obligación de promover, respetar, proteger y garantizar los derechos humanos de conformidad con los principios de universalidad, interdependencia, indivisibilidad y progresividad. En consecuencia, el Estado deberá prevenir, investigar, sancionar y reparar las violaciones a los derechos humanos, en los términos que establezca la ley.

Esta reforma es un avance importante para articular de manera coordinada y enérgica las acciones necesarias para seguir la línea del desarrollo sustentable, sin embargo, hay cambios estructurales que han quedado pendientes y que serán obstáculo para cumplir con esta meta.

\section{POLICÍA COMUNITARIA Y GRUPOS DE AUTODEFENSA: MOVIMIENTOS DISTINTOS QUE COMPARTEN EL MISMO OLVIDO}

Ante la práctica deficiente o casi nula del precepto 1ero Constitucional y la conjugación de políticas de seguridad públicas contrarias a los derechos humanos, el hartazgo ciudadano se materializó en movimientos armados de parte de la ciudadanía. Y es que cabría recordar que, la historia de México se ha forjado sobre guerras, sobre estas disputas sangrientas reclamando acceso a la justicia y a la igualdad.
Entonces, en tiempos presentes, las carencias por parte del Estado siguen presentes, y la población igualmente reclama la ausencia de seguridad pública, por lo que estos movimientos son más fáciles que se presenten, puesto que existe toda una red histórica y de actores que los reproducen.

Aunado a estos elementos, ¿qué otros factores se suman a la explicación del incremento de la violencia, de la presencia del crimen organizado y de la criminalidad en la región? Las políticas de ajuste estructural y la reestructuración económica, política y social, que contribuyeron a configurar un mercado exitoso de ilegalidades, con énfasis en las drogas. Las transformaciones neoliberales del Estado relacionadas con cuestiones de seguridad, corrupción y protección política. La violencia como parte de una desregulación económica y cambios en los mercados informales ilegalescriminales (Maldonado, 2012, p. 8).

El Estado mexicano ha adoptado las políticas globales neoliberales, las cuales han ido en contra de cualquier precepto de desarrollo sustentable, así como, antagónicas totalmente con los Objetivos del Milenio, es decir, en favor de un desarrollo íntegro. Y que, en palabras de Maldonado (2012), estas políticas han dado como resultado reestructuraciones en la nación, de índole económica, política y social, haciendo énfasis en las regiones donde el narcotráfico se ha asentado. Y que, para el caso particular de Michoacán, emergió un poderoso narcotráfico regional que ha desafiado a las instituciones (2012, p. 8).

Por otro lado, hay que tener presente la forma 
en que el narcotráfico se fue instalando en la dinámica mexicana. En los años 60, con los movimientos globales, tanto económicos, como las guerras que se presentaban entonces, comienza esta era en donde las drogas, entran en la dinámica neoliberal, y da una importante transición hacia una visión empresarial de las mismas. Las plantaciones de drogas, para su procesamiento, comercialización y consumo, ya bajo una dinámica de producción, que entonces se toman acciones de destrucción y aseguramiento de las mismas. Para los años setenta, las cifras oficiales señalan un porcentaje elevado de destrucción y aseguramiento de droga. Por ejemplo, se destruyeron trece millones y medio de plantas de amapola, más de treinta hectáreas y alrededor de dos mil plantíos de amapola, varios kilos de opio y heroína y casi una tonelada de semilla. En cuanto a la mariguana, se destruyó una y media toneladas listas para el consumo (hablando particularmente del caso de Michoacán) (Maldonado, 2012).

De forma paralela al aumento en la violencia generada por la guerra contra el narcotráfico, se escuchan de movimientos ciudadanos que van cobrando fuerza y presencia, principalmente en estados como Guerrero y Michoacán. la presencia similar a estos se ha extendido, pero ellos son los más emblemáticos. En ambos estados se vieron inmersos en un ambiente de terrible inseguridad y delincuencia, y que, debido al abandono, omisión, en reiteradas ocasiones y a la complicidad de las autoridades en todos los niveles de gobierno, es que buscan encargarse de la propia seguridad de sus comunidades.
Los grupos de autodefensa de Michoacán, surgen en febrero del 2013, reaccionando o siendo una respuesta ante la oleada de violencia que se había desatado desde el inicio de la guerra contra el narcotráfico (2007). Que si bien está previsto en el artículo 21 Constitucional que la seguridad pública:

“...es una función a cargo de la Federación, el Distrito Federal, los Estados y los Municipios, que comprende la prevención de los delitos; la investigación y persecución para hacer la efectiva, así como la sanción de las infracciones administrativas, en los términos de la ley, en las respectivas competencias que esta Constitución señala"

En este sentido, organizarse como ciudadanos en torno a una seguridad pública contravendría el artículo 21, incluso el 17 Constitucional señala que, "Ninguna persona podrá hacerse justicia por sí misma, ni ejercer violencia para reclamar su derecho". Sin embargo, la seguridad pública es un derecho humano, y el Estado mexicano ha dejado de garantizarla, por lo que está cayendo en una falta grave. De acuerdo con Plascencia, "este derecho constituye un factor fundamental para la consolidación del sistema de libertades y la garantía del respeto irrestricto en el ejercicio, protección y promoción de los derechos humanos, lo que conlleva la exigencia de protección del orden público" (2013, p.2).

El caso de cómo la población mexicana, particularmente de los estados de Michoacán y Guerrero, se han organizado para tomar la seguridad pública en sus manos, ha suscitado interesantes discusiones, ya que, si bien los grupos de autodefensa caen en la ilegalidad al llevar a cabo funciones de este tipo, también el 
Estado ha caído en importantes violaciones a derechos humanos.

Los grupos de autodefensas que en tiempos recientes tomaron más presencia en el ámbito público, fueron los de Tierra Caliente, en el mencionado estado de Michoacán. Y que a diferencia de los grupos de autodefensa de Colombia, estos segundos, fueron creados por políticos, militares, empresarios y ciudadanos en general, para combatir la guerrilla.

Este tipo de movimientos ciudadanos de autodefensas es criticado severamente debido a que parece que se "están haciendo justicia por propia mano", sin embargo, la crítica debería ir en sentido contrario ya que las carencias institucionales e insustentabilidad en las estrategias de desarrollo han orillado a estas comunidades a actuar de manera drástica. Plasencia lo plantea de la siguiente manera:

La situación de violencia que se vive en estas comunidades del estado de Guerrero, en donde rige la ilegalidad y la impunidad, debido a que los servidores públicos han abandonado el ejercicio de la función en materia de seguridad pública, creando una victimización de la sociedad guerrerense, especialmente de los habitantes de estas comunidades, quienes ante la exclusión y el abandono han decidido tomar en sus propias manos la defensa de sus localidades en aras de alcanzar orden y seguridad. Este contexto explica por qué el 5 de enero de 2013 un grupo de aproximadamente 800 personas de los municipios de Ayutla de los Libres, Teconoapa, Florencia Villarreal y Copala tomaron las armas e instalaron retenes en la localidad de Ayutla con el objetivo de brindar seguridad a sus comunidades, bajo el argumento de luchar contra la delincuencia. (2013, p.7)

En este punto es necesario hace la distinción entre grupos de autodefensa y policía comunitaria. La conformación de la policía comunitaria no es contraria a la ley, de hecho, está prevista dentro de lo concerniente a las comunidades indígenas:
A. Esta Constitución reconoce y garantiza el derecho de los pueblos y las comunidades indígenas a la libre determinación y, en consecuencia, a la autonomía para:
I. Decidir sus formas internas de convivencia y organización social, económica, política y cultural. (Art. 2, Constitución).

Y en el artículo 115 se prevé:

Las comunidades indígenas, dentro del ámbito municipal, podrán coordinarse y asociarse en los términos y para los efectos que prevenga la ley.

Por lo tanto, la policía comunitaria de Guerrero es una figura contemplada en la Constitución pero que de igual forma que los grupos de autodefensa en Michoacán, han percibido la ineptitud y corrupción de las autoridades, por lo que se han entregado y comprometido más con las labores de salvaguardar la seguridad pública.

La policía comunitaria es coadyuvante del Ministerio Público, y se conforma en 1995, después de tres grandes asambleas en donde las autoridades gubernamentales estuvieron ausentes, lo que evidenció la indiferencia ante 
su apremiante necesidad de seguridad. Como resultado de estos diálogos, se crea la Policía Comunitaria, cuyos efectivos son voluntarios, sin goce de sueldo y quienes ponían a disposición a aquellos que observaban delinquiendo. Bajo este sistema, observaron un descenso considerable en la criminalidad, pero también se evidenció la corrupción de las autoridades. Entonces, en este sentido, la policía comunitaria se origina y sus bases son la autoprotección, al mismo tiempo que, la defensa de la tierra. Forma parte de su concepción de justicia colectiva y de auto organización en incluso de autogobierno. No se cubren el rostro, puesto que no son grupos de choque o que actúen en la ilegalidad y, al contrario, es un oficio del cual enorgullecerse, tanto a ellos mismos como a sus familias. Y fueron estas mismas causas las que dieron origen también al surgimiento de la Policía Comunitaria de Cherán, Michoacán (2011) y en otras poblaciones indígenas de la meseta purépecha. En ese año las comunidades indígenas de esta zona se organizaron a sí mismas, tomaron las armas y se enfrentaron a los talamontes que estaban apoyados por los cárteles de La Familia Michoacana y Los Templarios (Olmos, 2013).

El sistema de policía comunitario que han implementado es muy interesante, ya que participa quien tiene vocación, hay elección de sus miembros y tienen una propuesta interesante acerca de la reeducación. Por ejemplo, la sanción es el trabajo a favor de la comunidad y ésta misma busca hacerles reflexionar acerca de la falta que cometieron (policía comunitaria, recuperado 2014).

El caso de Michoacán es diferente, los grupos de autodefensa son ciudadanos (no entran en comunidad indígena) que se organizaron para hacer frente a la delincuencia organizada que continuamente los extorsionaba, amenazaba y agredía. En sentido estricto están violando la ley, además de que como ciudadanos no se tiene la facultad de uso y portación de armas exclusivas del ejército. En este estado, particularmente la zona de Tierra Caliente, se conformó como escenario de acción y negociación de la delincuencia organizada, esto gracias a diferentes elementos como por ejemplo la geografía de la región, la vulnerabilidad de la población, a las instituciones debilitadas y que, de alguna manera, también forman parte de una criminalidad organizada.

La cruenta disputa cuyo escenario es la Tierra Caliente descansa sobre una lógica económica poderosa: las enormes riquezas derivadas del control del tráfico de marihuana, amapola y anfetaminas, producidas localmente, y de la cocaína, contrabandeada por los michoacanos desde Colombia, Venezuela y Centroamérica hacia Estados Unidos. El origen de todo esto no es muy lejano. Se remonta a comienzos de la década de los ochenta, cuando algunos hombres se organizaron la siembra dispersa de marihuana bajo el liderazgo de Carlos Rosales Mendoza, un fumador empedernido con tos permanente. El tísico lo Ilamaban. (Padgett y Martínez, 2011, p.29).

El grupo criminal más fuerte de ese estado fue la Familia Michoacana, cuyos ajustes y cambios dentro de la organización han originado a los Caballeros Templarios, lo que ha generado un control por la plaza que ha repercutido en la 
seguridad de los ciudadanos. Un ejemplo de lo ordinario por aquellos rumbos es:

- ¿Desde hace cuánto comenzó el control de la Familia sobre el negocio?

Unos 10 años. Se puede hablar de ventajas y desventajas. Una ventaja es que la policía no extorsiona como antes hacía: ahora tú pagas tu impuesto de $\$ 120$ por kilo que sacas y ya está. La organización también frenó a los bandidos, que robaban al productor y al intermediario.

- ¿Y los marinos?

Son más cabrones. Tanto en el enfrentamiento como en el soborno. Pegan más. El problema también es que los militares llegan, golpean, violan, roban. (Padgett y Martínez, 2011, p.30).

El crecimiento y posicionamiento de la delincuencia organizada no hubiera sido posible sin el hecho de evidenciar su poderío frente al gobierno municipal y estatal. Ello quedó evidenciado ante la opinión pública cuando las autoridades federales dieron a conocer videos y fotografías incautados al crimen organizado. En uno de ellos, difundido en abril de 2014, aparecía el secretario particular del gobernador Fausto Vallejo (2009-2014), Jesús Reyna, en tratos con el líder de Los Caballeros Templarios, Servando Gómez (La Tuta) (Guerra, 2015, p.8).

El movimiento de los grupos de autodefensa de Michoacán (ADM), surgió con unos cientos de hombres, y en poco tiempo, eran cientos y eran comunidades, los que estaban unidos exigiendo lo que el Estado mínimamente está obligado a brindar; paz, seguridad y tranquilidad. Una región en donde el terreno es accidentado, las redes criminales y comerciales (narcotráfico) han crecido mucho. El desarrollo y el progreso que en cierto periodo se pretendió impulsar, no significó un inhibidor de la violencia y la delincuencia, aunado a esto, ante la cruzada contra las drogas, que se llevó a cabo en el gobierno de Felipe Calderón, lejos de aminorar la presencia criminal, se incrementó. Esta sensación se presentó a lo largo del país, intensificándose en regiones como ésta, por ejemplo. Especialmente a partir de 2010 empezaron a secuestrar y extorsionar a los vecinos. Cien pesos por vivir en tu propia casa, 150 por cada máquina en la tienda de videojuegos... A La Ruana lo peor llegó cuando se hicieron del control de las cinco empacadoras de limón del pueblo, la fuente de su riqueza, y comenzaron a pagar dos pesos por $\mathrm{kg}$ cuando su precio en el mercado era de 3.5 pesos por kilogramo (Guerra, 2015).

\section{REFLEXIONES FINALES}

La problemática de inseguridad continúa de forma alarmante y sin que las autoridades o la misma delincuencia organizada de tregua a la ciudadanía quien es quien sufre de manera directa el goce pleno de sus derechos humanos y la capacidad de vivir dentro de una lejana sustentabilidad. Han pasado aproximadamente 8 años desde que el movimiento de las ADM se presentó por primera vez, casi una década en donde la situación ha sido como de una guerra de baja intensidad. Un conflicto bélico en donde toda la energía, todos los recursos, se has desgastado y desviado para poder sobrevivir ante un contexto sumamente hostil y agresivo. ¿Cómo transitar hacia un camino de 
la reconciliación, la justicia y la paz?, ¿cómo reconstruir las instituciones y el trabajo y cercanía con la población?, son algunas de las interrogantes y tareas que quedan en las cuales trabajar. ¿Cuándo este espiral de violencia volverá a estallar?

La inseguridad pública tiene causas estructurales, hay impunidad y prácticas corruptas normalizadas e institucionalizadas. De hecho, la criminalidad en general, y la delincuencia organizada y de cuello blanco en particular, responde además de factores sociales y cultures a los políticos y económicos. A pesar de que el concepto de desarrollo sustentable tiene presencia en el discurso oficial, lo que se observa en la realidad es que no hay todavía una integración estratégica-estructural entre los diferentes elementos que integran tal desarrollo. Hay una vulnerabilidad marcada en gran parte de la población mexicana, por lo que la delincuencia organizada, alimentada por la corrupción cultural e institucional, seguirá lastimándola constantemente.

\section{TRABAJOS CITADOS}

Aguilera, R. (2008). Participación ciudadana, servicios públicos

y multiculturalidad en Cienfuegos, D. y Rodríguez,

L. (Coord.), Actualidad de los Servicios Públicos en Iberoamérica, México, UNAM.

Armendares, P. (s/f). La política migratoria de Trump. Imapctos para los migrantes mexicanos y sus comunidades. Edit., Instituto Belisario Domínguez, La_politica_migratoria_ Trump_distribucion.pdf (senado.gob.mx)

EFEVerde, El tráfico ilegal de madera se dispara en Latinoamérica, 21 enero 2018. El tráfico ilegal de madera aumenta en Latinoamérica (efeverde.com)
Cervantes, J. (2013). Grupos de autodefensa, síntoma del hartazgo. Recuperado 12 de enero 2014. www.proceso. com.mx

CONEVAL (2020), Índice de rezago social 2020, edit. Coneval, PPT_resultados_IRS_2020.pdf (coneval.org.mx) CNDH. (2013) Informe especial sobre los grupos de autodefensa y la seguridad pública en el estado de Guerrero. México, $\mathrm{CNDH}$.

Fuentes Díaz, Antonio, \& Paleta Pérez, Guillermo (2015). Violencia y autodefensas comunitarias en Michoacán, México. Iconos. Revista de Ciencias Sociales, (53),171186. [fecha de Consulta 1 de Junio de 2021]. ISSN: 13901249. Disponible en: https://www.redalyc.org/articulo. oa? id=50941149009

Guerra Manzo, Enrique (2015). Las autodefensas de Michoacán. Movimiento social, paramilitarismo y neocaciquismo. Política y Cultura, (44),7-31. [fecha de Consulta 1 de Junio de 2021]. ISSN: 0188-7742. Disponible en: https://www. redalyc.org/articulo.oa?id=26743130002 Olmos, J. (2013).

Policías comunitarios y grupos de autodefensa. Recuperado 12 de enero 2014. www.proceso.com.mx

Olmos, J. (2013). Policías comunitarios y grupos de autodefensa. Recuperado 12 de enero 2014. www.proceso.com.mx

Policía Comunitaria (s.f). Recuperado el 30 de junio de 2014. www.policiacomunitaria.com

Padgett, H. y D. Martínez, La República Marihuanera, 23 enero 2012. Emeequis

Santos, G. Villarreal. (2009). Estados fallidos: definiciones conceptuales. Subdirección d política exterior.

Rosagel, S. (2011). Activistas: pendiente de Estado. Recuperado el 30 de septiembre de 2014, http://www.sinembargo. $\mathrm{mx} / 08-08-2011 / 21738$.

Robles, F., Hernández, C. y Hernández, N. 2019. “¿Qué pasa en el campo mexicano?: la violencia en los municipios rurales, una aproximación a su estudio", serie documento de trabajo Nº 251. Rimisp México y Centroamérica, México.

Revista Proceso (2014). Soldados balearon a 11 y mataron a 4, incluida una niña, reviran autodefensas. Recuperado 16 de enero 2014. www.proceso.com.mx 
Galicia, J. (2014). Autodefensas, con presencia en 11 estados: CNDH. Recuperado 20 de abril de 2014. http://www. sexenio.com.mx/articulo.php? $\mathrm{id}=42669$

Sánchez, V. (2014). La geografía de las autodefensas. Recuperado 20 de abril 2014., http://www.animalpolitico. com/blogueros-causa-en-comun/2014/01/28/la-geografiade-las-autodefensas/

\section{Carla Monroy Ojeda}

Afiliación: Universidad de ciencias de la Seguridad, México.

Doctora en Criminología UANL; Profesora Investigadora de Universidad de Ciencias de la Seguridad, de la Facultad de Biología, Facultad de Derecho y Criminología de la UANL (líneas de investigación Política criminal ambiental y Prevención social del delito). Miembro del Sistema Nacional de Investigadores Nivel 1 CONACYT. Correo de contacto: crlmonroy@gmail.com 